\section{Validation of the Work Limitations Questionnaire in Brazilian Army military personnel}

\author{
Juliane Umann' \\ Rodrigo Marques da Silva ${ }^{2}$ \\ Cristilene Akiko Kimura ${ }^{3}$ \\ Vitor Cauê Lopes ${ }^{4}$ \\ Dirce Bellezi Guilhem ${ }^{5}$
}

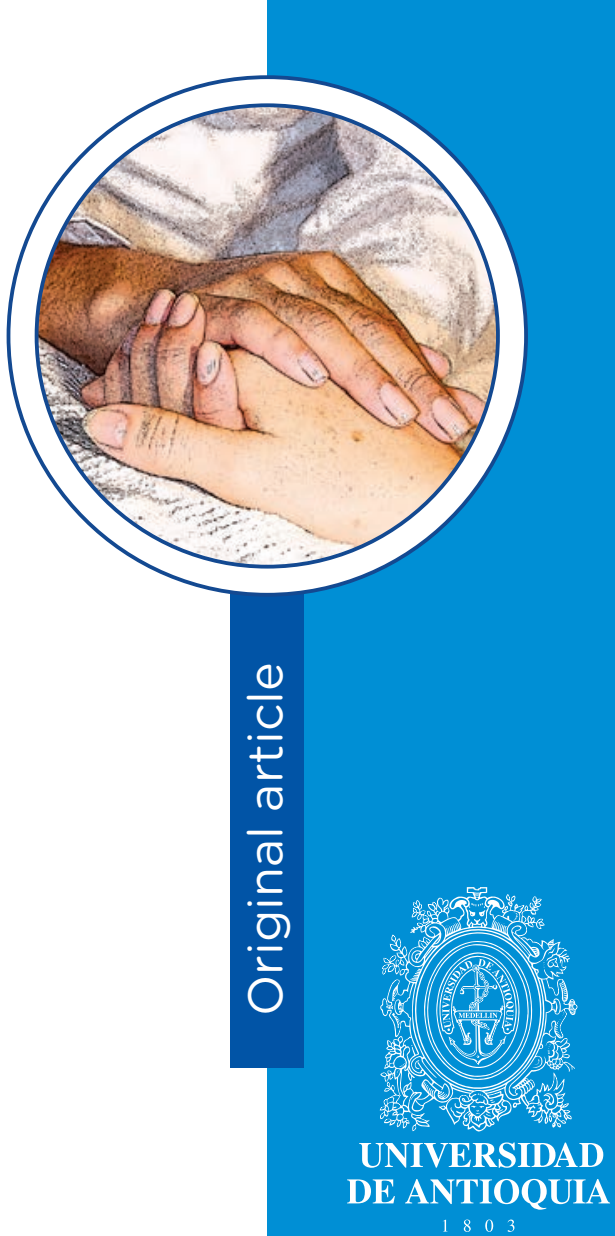

1 Nurse, PhD. Nurse of the Brazilian Army. São Gabriel (RS), Brazil.

email: juumann@hotmail.com

2 Nurse, PhD. Professor, Faculdade de Ciências e Educação Sena Aires Sena Aires-FACESA, Valparaíso de Goias (GO), Brazil.

e-mail: marques-sm@hotmail.com

3 Nurse, PhD. Academic Supervisor, FACESA, Valparaíso de Goias (GO), Brazil. email: cris.akiko7@gmail.com

4 Nurse, Master. Professor, Associação Juinense de Ensino Superior-AJES, Juína (MT), Brazil. email: victor caue@hotmail.com

5 Nurse, PhD. Professor, University of Brasília-UnB, Brasília, (DF), Brazil.

email: guilhem@unb.br

Conflicts of interest: none.

Received: May 5th, 2018.

Accepted: September 19th, 2018.

How to cite this article: Umann J, Silva RM, Kimura CA, Lopes VC, Guilhem DB. Validation of the Work Limitations Questionnaire in Brazilian Army military personnel. Invest. Educ. Enferm. 2018; 36(3):e06.

DOI: $10.17533 /$ udea.iee.v36n3e06 adjustment (absolute and incremental) and residues indexes demonstrated satisfactory values. The Alphas in domains ranged from 0.68 (output demand) to 0.79 (time management) in domains, evidencing reliability

\section{(c) $\frac{10(2)(2)}{{ }_{\mathrm{BY}} \mathrm{NC}}$}


for the WLQ. Conclusion. We confirm the construct validity of the WLQ to assess presenteeism in Brazilian military staff.

Descriptors: occupational health; military personnel; validation studies; psychometrics

\section{Validación del cuestionario de limitaciones en el trabajo en militares del ejército brasileño}

Objetivo. Validar el Cuestionario de Limitaciones en el Trabajo (WLQ) para evaluar el presentismo en militares del ejército brasileño. Métodos. Se trata de un estudio de validación de pruebas conducido con 125 militares de una organización militar del Ejército Brasileño. Se aplicó un formulario para la caracterización sociodemográfica y funcional y el WLQ, compuesto por 25 ítems. La validez de constructo se evaluó mediante del análisis factorial confirmatorio. Resultados. Se confirmó la estructura interdependiente de los dominios para explicación del presentismo en el grupo de estudio en cuatro dominios: demanda de producción, demanda mental, demanda física y gerencia del tiempo. La mayoría de los ítems presentaron cargas factoriales entre 0.5 y 0.7 y los índices de ajuste (absolutos e incrementales) y de residuos tuvieron valores satisfactorios. La confiabilidad por dominio varió de 0.68 (demanda de producción), 0.73 (demanda física) y 0.79 (gerencia del tiempo), evidenciando confiabilidad del WLQ. Conclusión. El WLQ es un instrumento confiable y válido para evaluar el presentismo en militares del ejército brasileño. 
Descriptores: Salud Laboral; Personal Militar; Estudios de Validación; Psicometría.

\section{Validação do Questionário de Limitações no Trabalho em militares do Exército Brasileiro}

Objetivo. Validar o Questionário de Limitações no trabalho (WLQ) para avaliar presenteísmo em militares do Exército Brasileiro. Método. Trata-se de uma pesquisa de validação de um teste realizada com 125 de militares de uma organização militar do Exército Brasileiro. Aplicaram-se um Formulário para caracterização sóciodemográfica e funcional e o WLQ, composto por 25 itens. A validade de constructo foi avaliada por meio de análise fatorial confirmatória. Resultados. Confirmou-se a estrutura interdependente dos domínios para explicar o presenteísmo na população de estudo em domínios: demanda de produção, demanda mental, demanda física e gerência do tempo. A maioria dos itens apresentou cargas fatoriais entre 0.5 e $0.7 \mathrm{e}$ os índices de ajuste (absolutos e incrementais) e de resíduos apresentaram valores satisfatórios. Os Alfas por domínio variaram de 0.68 (demanda de produção) a 0.79 (gerência do tempo), evidenciando confiabilidade do WLQ. Conclusão. Confirmouse a validade de constructo do WLQ para avaliar presenteísmo em militares do exército brasileiro.

Descritores: saúde do trabalhador; militares; estudos de validação; psicometria. 


\section{Introduction}

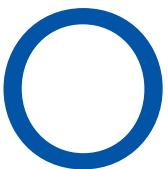

rganizational trends in the field of occupational health, especially those focused on performance and productivity, have been frequently debated due to their consequent managerial, economic and legal repercussions in relation to the demands of the labor market. ${ }^{(1)}$ From this, new concepts arise and have been studied in order to promote greater understanding of the work-health-disease relationship in the perspective of prevention of damages against the mismatches between demands and capacity for labor.

In this sense, presenteeism was created to describe the increasing propensity of workers to spend long hours in the work environment when they feared for their work. ${ }^{(2)}$ Usually more accepted in investigations on occupational health, its concept describes the relationship between illness and productivity loss. Thus, despite the complaints and health problems, the worker is present in the workplace, but the performance of activities inherent to their functions occurs in an unproductive way. ${ }^{(3)}$ Thus, two different behaviors are possible for the worker, namely: carrying out extensive workdays as a reflection of their commitment or a way of facing the continuous labor insecurity; as well as going to work while being sick and, because of their medical conditions, not being productive. ${ }^{(4)}$

The culture of presenteeism has been suggested from the different incidences found in distinct occupational groups, without the mediating collective mechanisms having been investigated. ${ }^{(5-8)}$ In this logic, some occupations, such as the military, would be more prone to presentism, due in part to professional identity, ethical values and principles and specific characteristics such as hierarchy and permanent availability. ${ }^{(9)}$ Moreover, it is possible that the level of identification with the work and its central role in life are crucial to the understanding of presenteeism in this population. ${ }^{(10)}$ For this purpose, valid and reliable tools for measuring presenteeism are essential to diagnose this phenomenon in the organizational context and, consequently, to estimate the impact of diseases on workers' productivity. However, measuring presentism is a challenge because it is a non-palpable, apparently hidden condition that requires the recognition of the professional about his or her best and worst condition for the development of the activities at work. Also, direct measurement of productivity is a difficult task, especially in occupations whose institutional culture encompasses striking traits of professional identity. Therefore, depending on how the presenteeism is conceptualized and measured in the investigations, it has different implications to the health and well-being of the professionals.

From the health point of view, attention to presenteeism provides not only a means to verify the associated productivity losses, but also important connections between having a medical condition, defining oneself as a patient and the behaviors associated with returning to work admitting the condition 
of being sick. In due course, the interest for performing this research by nurses is justified by the recent insertion and expansion of vacancies for these professionals within the scope of the Brazilian Army. Also, the increasing participation of this professional category in studies on health and psychosocial aspects of the work, which enable the identification of changes in this scope among the military staff, implies appropriate care and/or pertinent referrals. With the participation of nurses in military medical-hospital units where assistance is provided to their dependents and reservists, this benefit is extended to a significant portion of the civilian population.

In this context, although it is a relatively recent and complex-to-measure concept, there are already instruments to measure presenteeism applied in different realities, ${ }^{(11)}$ such as the Work Limitations Questionnaire (WLQ) ${ }^{(12)}$ and the Stanford Presenteeism Scale (SPS-6), ${ }^{(13)}$ and both have been validated in Brazil. ${ }^{(14,15)}$ Of these, the WLQ is the one whose psychometric properties have been most extensively tested to assess the impact of general health and specific conditions on individuals' productivity. ${ }^{(5)}$ It was translated and validated for the Brazilian reality together with employees and graduate students for the evaluation of presenteeism from the measure of lost productivity associated with the interference of health problems in the performance of work activities. ${ }^{(14)}$ From its validation, only one study including hospital nurses was performed and, through Cronbach's alpha, had its reliability attested, with values ranging from 0.78 to 0.90 . (16) However, its validation for service people was not verified in the national and international literature. Moreover, this instrument had its validity analyzed almost ten years ago, a condition that can affect its stability (reliability) and validity, that is, its capacity to measure what it is proposed to measure. ${ }^{(17,18)}$ In view of the above, the objective of this study was to validate the Work Limitations Questionnaire (WLQ) for this population.

In the field of nursing, specifically nursing work, the WLQ allows the identification of cases of presenteeism based on the productivity loss in the occupational space, which enables identifying the impact of the labor process on workers' health and the development of actions to minimize related causal factors. In order to expand the nurse's field of action, the validation of the WLQ for application in service people will allow these benefits to be extended to evaluate the work-health relationship in the context of the Brazilian Army.

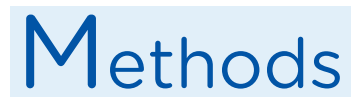

This is a methodological research carried out with 125 service people from a military organization of the Brazilian Army of Porto Alegre (Brazil). Military members of the permanent staff of the said Military Organization were included, whose graduations consist of officers, lieutenants, sergeants, corporals and soldiers. The following exclusion criteria were defined: soldiers of variable staff (providing compulsory temporary service), service people in sick leave throughout the period of data collection or in leave by any reason. The research protocol was applied in October 2016 and was composed by the following selffilling instruments: sociodemographic and labor characterization form and Workplace Limitations Questionnaire (WLQ). The characterization form addressed the following sociodemographic variables: date of birth, sex, marital status and schooling level. The labor variables included training, reassignment information, daily working hours (considering the number of hours worked after the end of the workday), relationship to military service (temporary or career) and time of work in the Army.

The WLQ is an instrument composed of 25 items (Table 1) encompassing the multidimensional nature of the functions developed in the occupational environment, grouped into four domains of labor limitation: Time management, with five items (question 1) that deal with difficulties in complying schedules and tasks in due time; Physical demand, with six items (question 2) assessing the ability to perform tasks requiring body strength, endurance, movement, 
coordination and flexibility; Mental-interpersonal demand, with nine items (questions 3 and 4) assessing the difficulty in performing cognitive tasks at work and interacting with people at work; and Output Demand, with five items (question 5) referring to decreased ability to achieve, in a timely manner, the quantity and quality of completed work. ${ }^{(14)}$

Table 1. Items that make up the WLQ. Porto Alegre, 2016.

\section{Question}

1. In the past 2 weeks, how much of the time did your physical health or emotional problems make it difficult for you to do the following?

WLQ1a: handle the workload

WLQ1b: prepare to leave easily at the beginning of a working day

WLQ1c: start on you job as soon as you arrived at work

WLQ1d: do your work without stopping to take breaks or rests

WLQ1e: stick to a routine or schedule

2. In the past 2 weeks, how much of the time were you able to...

WLQ2a: ...walk or move around different work locations (for example, go to meetings) without difficulty caused by physical health or emotional problems?

WLQ2b: ...lift, carry and move objects with more than 5 kilos, without difficulty caused by physical health or emotional problems?

WLQ2c: ....sit, stand, or stay in one position for longer than 15 minutes while working, without difficulty caused by physical health or emotional problems?

WLQ2d: ... repeat the same motions over and over again while working, without difficulty caused by physical health or emotional problems?

WLQ2e: ... tilt, turn, or stretch to reach objects at work, without difficulty caused by physical health or emotional problems?

WLQ2f: ...use hand-held tools or equipment (for example, a phone, pen, keyboard, computer mouse, drill, hairdryer or sander) without difficulty caused by physical health or emotional problems?

3. In the past 2 weeks, how much of the time did your physical health or emotional problems make it difficult for you to do the following?

WLQ3a: work thinking only at work

WLQ3b: think clearly while at work

WLQ3c: do the work carefully

WLQ3d: concentrate on your work

WLQ3e: think without losing the thread when you are working

WLQ3f: read or see easily at work

4. In the past 2 weeks, how much of the time did your physical health or emotional problems make it difficult for you to do the following?

WLQ4a: speak with people in-person, in meeting or on the phone

WLQ4b: control your temper in front of people at work

WLQ4c: help others complete tasks

5. In the past 2 weeks, how much of the time did your physical health or emotional problems make it difficult for you to do the following?

WLQ5a: handle the workload

WLQ5b: work fast enough

WLQ5c: finish work on time

WLQ5d: do your work without making mistakes

WLQ5e: feel that you have done what you can do 
Each scale has a score ranging from 0 (limited none of the time) to 100 (limited all of the time). The score indicates the percentage of time, in the past 2 weeks, that the individual was limited to perform their tasks at work. Thus, if the score in the interpersonal-mental demand scale is 30 , it means that the individual was limited in 30\% of the time destined for the development of this type of task. After calculating all the scales, we can define the WLQ index, which represents a percentage of reduction in productivity when compared to a healthy individual.

For the storage and organization of information, a database was built in an Excel program (Office 2010) spreadsheet, where the sociodemographic variables and the items composing the instrument were inserted. In addition, for the quality control of the data, the data was double typed by two independent typists. After the construction of the database, the data were analyzed in the Statistical Package for Social Sciences program (SPSS, version 10.0) and in the AMOS complement of the same software, used for confirmatory factor analyzes. Pearson's correlations were used to evaluate the interdependence of factors in explaining presenteeism. The factorial loads allowed us to analyze the contribution of the items to their respective factors. The Cronbach's alpha was used to analyze the reliability of the WLA from the evaluation of its internal consistency.

We considered the recommendation to use at least one absolute and one incremental adjustment indicator, in addition to the $\chi 2$ and the Degree of Freedom (DF), as well as a poor quality fit index (residue). ${ }^{(19)}$ Thus, the absolute measures used were $\chi 2(\mathrm{Fit}=>0.05)$, normalized $\chi 2$ (Fit $=<3.0$ ), based on DF; Quality of Fit Index (QFI) (Fit=>0.95). The following incremental indicators were used: Comparative Fit Index (CFI) ( Fit $=>0.92)$ and Tucker Lewis Index (TLI) (Fit =>0.92).(19) As a measure of poor quality of fit, the following stand out: Root of the Mean Square Error of Approximation (RMSEA) ( $F i t=r<0.08$ considering $\mathrm{CFI}>0.92$ ) and Standardized Root Mean Residue (SRMR) ( Fit $=r<0.09 \quad$ considering $\mathrm{CFI}>0.92)$. (19) Also, the variance inflation factor was used to confirm the presence of collinearity (VIF $>10$ ). The ethical precepts, provided for in Resolution $466 / 12$ of the National Health Council, were respected in the conduction of this research, and the project received approval by CEP/UFRGS under No. 1.679.372, Approval Certificate No. 57814616.5.0000.5347. It should be noted that, after exposure of the study objectives, all individuals who accepted to participate in the study signed the Informed Consent Form before receiving the research protocol.

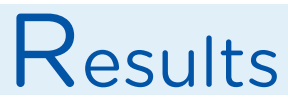

Of the 150 service people eligible for the survey, four were on sick leave and 21 were withdrawn for involvement in duties outside barracks throughout the data collection period. Thus, we had access to a population of 125 service people (24 officers and 101 soldiers), whose sociodemographic and functional characterization is presented in Table 2. 
Table 2. Sociodemographic and functional characterization of the 125 service people. Porto Alegre, 2016

\begin{tabular}{|c|c|c|c|c|c|}
\hline Variable & $n$ & $\%$ & Mean (SD) & Median & Minimum-Maximum \\
\hline Age & 125 & & $27.9(8.6)$ & 24.00 & $18-53$ \\
\hline \multicolumn{6}{|l|}{ Sex } \\
\hline Female & 10 & 8 & & & \\
\hline Male & 115 & 92 & & & \\
\hline \multicolumn{6}{|l|}{ Marital status } \\
\hline Married/partner & 87 & 69.6 & & & \\
\hline Single & 33 & 26.4 & & & \\
\hline Divorced/separated & 5 & 4 & & & \\
\hline \multicolumn{6}{|l|}{ Schooling } \\
\hline Primary education & 8 & 6.4 & & & \\
\hline Secondary education & 74 & 59.2 & & & \\
\hline Higher education & 32 & 25.6 & & & \\
\hline Graduation & 11 & 8.8 & & & \\
\hline Time of work in the Army & & & $7.96(8.59)$ & 5 & $1-34$ \\
\hline \multicolumn{6}{|l|}{ Relationship } \\
\hline Temporary & 72 & 57.6 & & & \\
\hline Career & 53 & 42.4 & & & \\
\hline Workload & & & $8.12(0.82)$ & 8 & $4.5-14$ \\
\hline Extra hours & 67 & 53.6 & $0.88(1.14)$ & 1 & $0-6$ \\
\hline No reassignment & 92 & 73.6 & & & \\
\hline
\end{tabular}

Since the hypotheses to be tested have theoretical basis and were supported by previous empirical analyzes in similar populations, the confirmation of the factorial structures in the constructs could be established with the techniques of confirmatory factorial analysis. In Figure 1, we present the results obtained in the confirmatory factor analysis of the measurement model of the Work Limitations Questionnaire (WLQ). 


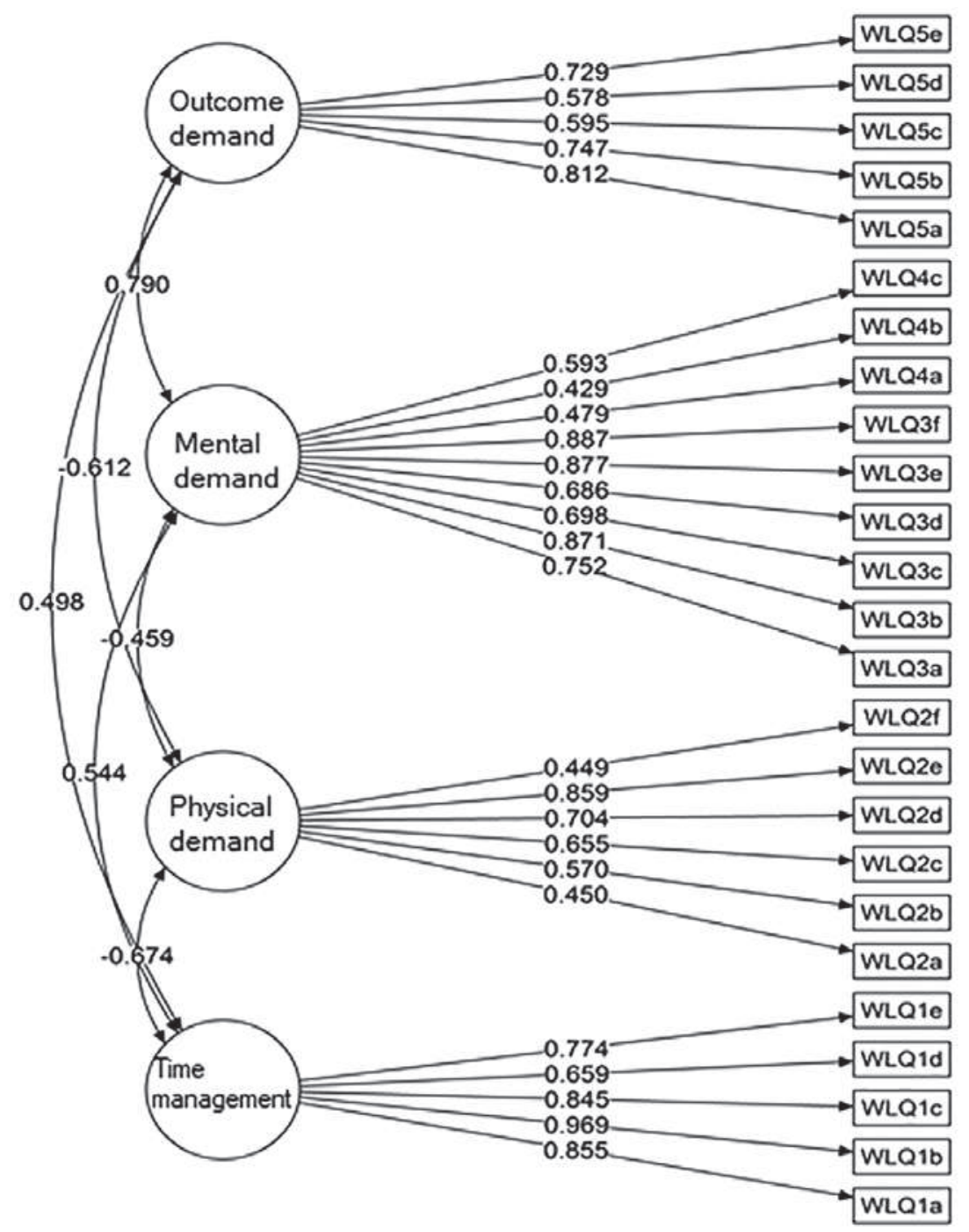

Figure 1. Model of the Measurement of the Work Limitations Questionnaire (WLQ). Porto Alegre, 2016

Satisfactory correlations were verified, although with values just above or below the defined limit, confirming the interdependent structure of domains for the explanation of presenteeism in this population. As for factor loads, most of the items presented satisfactory values, according to the cut-off point established (between 0.4 and 0.7). The items WLQ1a (Time Management); WLQ2e (Physical Demand); as well as WLQ3b,
WLQ3e and WLQ3f (Mental Demand) presented values above 0.85 . However, the VIF values found did not confirm collinearity of these items, as follows: 3.444 (WLQ3b), 4.158 (WLQ3e), 3.815 (WLQ3f), 2.870 (WLQ2e) and 1.740 (WLQ1a).

Cronbach's alpha was 0.79 for the Time Management domain, 0.73 for Physical Demand, 0.78 for Mental Demand, 0.68 for Outcome Demand, and 0.89 for all 25 items 
of the instrument, showing satisfactory internal consistency to the instrument. Although some alpha values were slightly below and factorial loads slightly above expectations, considering the fit indices obtained for the factorial structure (Table 3), no items were excluded from the scale.

Table 3. Fit indexes and poor quality of fit obtained for the WLQ. Porto Alegre, 2016

\begin{tabular}{lcc} 
& Observed Values & Expected Values \\
Absolute Measures & & \\
$\chi 2$ & 643.811 & $>0.05$ \\
DF & 269 & - \\
Normalized $\chi 2(\chi 2 / D F)$ & 2.393 & $<3.0$ \\
$P$-value & 0.000 & $<0.05$ \\
QFI & 0.962 & $>0.95$ \\
Incremental Measures & & \\
CFI & 0.941 & $>0.92$ \\
TLI & 0.935 & $>0.92$ \\
Poor Quality Fit & & \\
RMSEA & 0.106 & $r<0.08$ \\
WRMR & 1.047 & $r<1.00$ \\
\hline
\end{tabular}

The values found for the absolute and incremental measurements were satisfactory. The indexes of poor quality of fit were slightly above expectations. However, given the presence of residues (difference between observed and expected values) within an acceptable limit and the adequacy of the data in the other indicators, no changes were made. Thus, the construct validity of the Work Limitations Questionnaire was validated to evaluate presentism in service people of the Brazilian Army.

\section{Discussion}

Until the 1970s, researchers used exploratory factor analysis techniques to achieve both exploratory and confirmatory objectives. Nowadays, the new techniques of confirmatory factorial analysis can reach the same objectives when reproducing the factorial structure and confirm a theory. ${ }^{(20)}$ In this sense, the factorial analysis tested and confirmed the fit of the WLQ structure previously defined in the literature in empirical studies. ${ }^{(14)}$ This phase is of utmost importance since it allowed validating the operational structure used to measure the constructs, also achieving satisfactory reliability, evaluated by the alpha statistics.

In its translated version and adapted culturally to Brazil, the WLQ was submitted to test-retest psychometric evaluation (intraclass correlation coefficient between 0.600 and 0.800 ) and internal consistency analysis (Cronbach's alpha between 0.808 and 0.904$).{ }^{(14)}$ The test-retest validation of the original scale indicated four domains, whose items presented corrected item-total correlations between 0.53 and 0.83 . The Cronbach alphas found varied from 0.88 to 0.91 , attesting reliability to the instrument. ${ }^{(12)}$ In a detailed analysis of the parameters used to evaluate the internal structure of the WLQ in this research, we found that the factorial loads, which provide indication on the contribution of the variable to explain the construct, presented satisfactory values. This indicates that the structural factorial of the instrument satisfactorily represents the existing theoretical model and, therefore, is operationally 
capable of measuring the presenteeism in service people of the Brazilian Army.

The variation found in the loads can be justified by the population $n$ in question and by the possible homogeneity in their characteristics, which affects the total variance. Also, in unifactorial instruments, due to their expected convergence of items, there may be multicollinearities, expressed by high factorial loads. The signs of potential collinearity, considered by the values found above 0.70 , when submitted to VIF were not confirmed. Therefore, although these variables present a common variance above that desired, this interaction is not enough for them to measure the same face of the phenomenon. In this sense, it must be considered that it may be difficult to obtain satisfactory indexes in confirmatory factorial solutions when non-normal distributions occur along with other breaches of assumptions, such as lack of independence between variables, measurement errors and an insufficient number of people in the sample. ${ }^{(20)}$

In the analysis of the quality of fit through the absolute, incremental and poor quality measures, the adequacy of these quality fit indexes was verified. However, slightly increased RMSEA/ WRMR values indicated the presence of residues, that is, differences between the values obtained in the observed and expected matrix. The higher this value, the more distinct are the models obtained with the empirical data in relation to that hypothesized by the researcher. Despite these changes in the residue indicators, when considering all the items, the satisfactory results in the absolute and incremental indicators and that the measures of residues are only a few tenths above the cut-off value, no WLQ items were excluded. Also, the researchers considered the retention or exclusion of items. Considering that they often contain essential information to evaluate the construct, small variations can be considered. It is known that the Confirmatory Factor
Analysis contributes to the process of review and refinement of psychological instruments and their factorial structures. Therefore, future applications of this method should be encouraged, especially if there is interest in possible modifications in the current internal structure of the WLQ or to investigate the invariance of the current structure between different groups or samples.

Conclusion. It was verified that the internal structure of the WLQ presents construct validity and satisfactory reliability for application in military staff of the Brazilian Army in order to measure presenteeism. This phenomenon is a potential catalyst for theoretical advances in occupational health, since it allows addressing the obscure areas between non-productivity (absenteeism) and excellence in the exercise of tasks at work. From the adequacy in the measurement systems, it is important to carry out investigations that evaluate the relationship of this construct to contextual and psychosocial characteristics in workers of different occupations, and especially among the military staff of the Brazilian Army. Thus, it will enable us to know its effects on organizational instances; to understand the real consequences of this type of activity on service people's health; and to develop preventive measures, stimulate the development of resilient characteristics and improve existing treatment methods. In the field of nursing, a specific version of the WLQ for military personnel will allow the identification of cases of presenteeism in the context of the Brazilian Army, allowing the nurse, especially the occupational nurse, to plan and implement the nursing process more effectively in this population, based on the causal factors related to the productivity loss at work, thus promoting occupational health and enabling managers to review the work processes in the military field. In this context, health benefits are expected for individuals exposed to adverse and/or potentially traumatic situations that pervade the military scope. 


\section{References}

1. Biron C, Saksvik O. Sickness Presenteeism and Attendance Pressure Factors: Implications for Practice. In: Cooper CL, Quick JC, Schabracq MJ, Editors. International Handbook of Work and Health Psychology. Nova Jersey: WileyBlackwell; 2009. p.77-92.

2. Aronsson G, Gustafsson K, Dallner M. Sick but yet at work. An empirical study of sickness presenteeism. J epidemiol community health. 2000; 54(7):502-09.

3. Johns G. Presenteeism in the workplace: a review and research agenda. J. Organiz. Behav. 2010; 31(4):519-42.

4. Cheryl I. AMA Manual of Style: A Guide for Authors and Editors. Oxford: Oxford University Press; 2016. Work Limitations Questionnaire: Publications and Presentations.10th ed. Oxford: Oxford UP; 2016.

5. Baptista PCP, Pustiglione M, Almeida MCS, Felli VEA, Garzin ACA, Melleiro MM. Nursing workers health and patient safety: the look of nurse managers. Rev. Esc. Enferm. USP. 2015; 49(n.spe2):122-8.

6. Umann J, Guido LA, Silva RM. Stress, coping and presenteeism in nurses assisting critical and potentially critical patients. Rev. Esc. Enferm. USP. 2014; 48(5):891-8.

7. Arumugam V, MacDermid JC. The Work Limitations Questionnaire (WLQ-25). J. Phys. 2013; 59(4):276.

8. Simmons A, Yoder L. Military resilience: a concept analysis. Nurs. Forum. 2013; 48(1):17-25.

10. D'Errico A, Viotti S, Baratti A, Mottura B, Barocelli AP, Tagna M, et al. Low back pain and associated presenteeism among hospital nursing staff. J. Occup. Health. 2013; 55(4):276-83.

11. Ospina MB, Dennett L, Waye A, Jacobs P, Thompson AH. A Systematic Review of Measurement Properties of Instruments Assessing Presenteeism. Am. J. Manag. Care. 2015 ;21(2):171-85.

12. Lerner D, Amick BC, Rogers WH, Malspeis S, Bungay K, Cynn D. The Work Limitations Questionnaire. Med. Care. 2001; 39(1):72-85.

13. Koopman C, Pelletier KR, Murray JF, Sharda CE, Berger ML, Turpin RS, et al. Stanford Presenteeism Scale: health status and employee productivity. J. Occup. Environ. Med. 2002; 44(1):14-20.

14. Soárez PC, Kowalski CCG, Ferraz MB, Ciconelli RM. Tradução para português brasileiro e validação de um questionário de avaliação de produtividade. Rev. Panam. Salud Pública. 2007; 22(1):21-8.

15. Paschoalin HC, Griep RH, Lisboa MTL, Mello DCB. Adaptação transcultural e validação para o português brasileiro do Stanford Presenteeism Scale para avaliação do presenteísmo. Rev. Latino-Am. Enfermagem. 2013; 21(1):388-95 .

16. Umann J, Guido LA, Grazziano ES. Presenteeism in hospital nurses. Rev. Latino-Am. Enfermagem. 2012; 20(1):159-66.

17. Hulley SB, Cumming SR, Browner WS, Grady DG, Hearst NB, Newman TB. Delineando a pesquisa clínica: uma abordagem epidemiológica. Porto Alegre; Artmed; 2008.

18. Damasio BF. Contribuições da análise fatorial confirmatória multigrupo (AFCMG) na avaliação de invariância de instrumentos psicométricos. Psico. USF. 2013; 18(2):211-20.

19. Hair JF, Black WC, Babin BJ, Anderson RE, Tatham RL. Análise Multivariada de Dados. 6. ed. Porto Alegre: Bookman, 2009.

20. Pilati R, Laros JA. Modelos de Equações Estruturais em Psicologia: Conceitos e Aplicações. Psic. Teor. Pesq. 2007; 23(2):205-16. 